\title{
Holistic Modelling and Parametric Study of Bathroom Solar Hot Water Heating System
}

\author{
Toyosi K. Oye \\ School of Engineering and Built Environment, Edinburgh Napier University, UK \\ Naren Gupta \\ School of Engineering and Built Environment, Edinburgh Napier University, UK \\ Keng Goh \\ School of Engineering and Built Environment, Edinburgh Napier University, UK
}

Abdelfateh Kerrouche

School of Engineering and Built Environment, Edinburgh Napier University, UK

Tosin T. Oye

School of Engineering and Built Environment, Edinburgh Napier University, UK

Received: March 29, 2021 Accepted: May 12, 2021 Published: May 23, 2021

doi:10.5296/emsd.v10i3.18519 URL: https://doi.org/10.5296/emsd.v10i3.18519

\begin{abstract}
One of the major issues facing the world in the 21 st century is climate change. However, sustainability has become a crucial concept to combat extreme consumption of environmental resources. The bathroom has been estimated to be the principal user of environmental resources in United Kingdom households. Therefore, the challenge that how a combined water and energy saving unit in the bathroom will contribute to the sustainability of the houses will remain unresolved. While the use of solar hot water technologies has been fundamental for energy efficiencies, this study reckons that lack of significant energy saving, and efficiency issues are based on the use of individual components and technologies it employed and concludes that a holistic approach is required to combat this issue. The method
\end{abstract}


this study presented adopts conceptual and mathematical concept that is based on holistic modelling to design for a bathroom unit using Polysun program. Parametric analysis was also conducted to know how change in variable parameters like location, load and switch-on temperatures will affect the performance of the system designed. This study uncovers the contribution of renewable energy source in the bathroom and the significant contribution it makes in levels of energy consumption and carbon emissions which is attributed to the sustainability of the bathroom system and contribution this in turn makes to tackle the climate change as part of a sustainability-based strategy.

Keywords: Bathroom, Water consumption, Energy consumption, Carbon emissions

\section{Introduction}

The effect of climate change is and will possibly keep on being a vital threat that experts need to manage globally in this century Ford and Berrang (2011).

Report from DEFRA in 2008 have highlighted that due to increasing population and the changes people have made in the way water is used in the UK, over $50 \%$ of UK water supply is now being delivered for domestic use. Therefore, resourceful management of water demand is of great importance in a domestic application (Jenkins et al., 2010; Parker, 2014; Water UK, 2016). Within cities, households deserve particular attention because households are a major building block of cities. Several studies have demonstrated that the heating of water within households dominates energy use of the residential water cycle (Arpke and Hutzler, 2006, Cheng, 2002).

Extreme energy and water consumption bring about various hidden sustainability consequences and most especially their combined nexus impact. The UN - Water and Energy sustainability in 2014 reports underlined the need to improve sustainability in a business-as-usual scenario, which may effectively impact the environment and risking the sustenance of social and economic developments. Studies from Water Wise in 2014 have also illustrated some major effects form extreme energy and water consumption that cause challenges with the social, economic and environmental sustainability, for example, degrading water surface because of contaminated surface overflow flushing into the water body, further water abstraction that causes degradation of the water body and high cost of maintenance with possible upgrade of water supply and treatment of waste-water mechanism. Water and energy nexus are vital resources, fundamental for human life on planet earth. These resources have been key for social, economic, and environmental development.

Increased energy consumption and demand, maintenance and upgrade costs and ageing infrastructure, drive the need to improve energy management to build up energy efficiency and resilience. Additionally, increased demand for fresh water, increased cost of treating water and aging water infrastructure drive the need to more efficient management of water resources. Total energy consumption is projected to grow by as much as $55 \%$ by 2040 as the combined effect of population growth and the improvement of living standards. The combined effect in a business-as-usual scenario might have outstanding effects over the environment and will put at risk maintaining the economic and social. Therefore, saving 
water can reduce the water bill, the energy use and bills, reduce the impact on local environment, and reduce carbon dioxide emissions by using less energy to pump, heat and treat the water (Oye et al., 2020a, Ritchie and Roser, 2019)

In the UK, a great many households are already making savings and making a difference engaging in water saving behavior, cutting their bills and conserving resources. But since the average home uses nearly 360 liters of water every day, there is still astonishing potential to save water, energy, and utility bills through further change. According to Energy Saving Trust (2013) showers, lavatories, baths, and bathroom sinks consume more than two-thirds $(68 \%)$ of household water. On average, $16 \%$ of a household's energy bill relates to heating water for showers, baths and hot water taps. This is on average about $£ 140$ a year. As a result, heated water contributes a lot to energy bills, bathroom uses the hottest water in the home, and so it is the responsible for the most water-related carbon emissions. The energy used to heat water for devices and appliances emits an average of $875 \mathrm{~kg}$ of $\mathrm{CO} 2$ per household per year. Therefore, the challenge that how a combined water and energy saving unit in the bathroom will contribute to sustainability of the houses will remain unresolved. A renewable-based option for bathroom system is proposed that can not only eradicate lower the levels of energy consumption and rate of carbon emissions, but also uncover the significance of and particular contribution renewables opportunities makes to the sustainability of the system (Oye et al., 2020b).

The basics of solar hot water heating and system modelling are comprehensively defined by the works of Duffie and Beckman (2012). Several other journals have worked on the concept of solar water heating for household applications and with different emphases both experimentally and analytically as regards its environmental performance in different academic field. Studies from (Kulkarni et al., 2008, Hobbi and Siddiqui, 2009, Ayompe, 2015, Gong, 2016, Koke and Kuhr, 2018, Alessandro, 2020) have concentrated on the relationship between solar hot water performance and design variables. Some examples of the latter are the storage tank size, the number of tanks, the solar collector area, the collector and heat exchanger flow rates, the hot water load profile, the hot water consumption, the auxiliary water heating device configurations, the cold make-up water replenishment profile, and the heat exchanger configuration. These authors have majorly concentrated on a system components or parameters at a time for system design or optimization i.e., solar collector, boilers, storage tanks etc. Academic studies from Maria, 2015 and, Ayompe, 2015 have achieve a moderate system efficiency $26 \%$ and $31 \%$ respectively in terms of the energy savings and carbon emission savings they both search for.

This study reckons that lack of significant energy saving, and efficiency issues are based on the use of individual components and technologies in the bathroom and concludes that a holistic approach is required to combat this issue. With the short comings of individual components in the bathroom, using holistic method of system interaction is important in the considerations of any modelling to significantly reduce energy use to heat water and its related emission in the bathroom. Even though the use of and optimizing of a single system component would be good benefit however, considering the energy efficiency of a smart system is limited to the capacity of its operations as this does not really increase the 
sustainability of the entire bathroom.

The idea of saving water and energy while employing the use of holistic method seems inevitable in improving environmental sustainability and indirectly focusing on achieving the ambitious climate neutrality goal. The holistic method does not only jointly improve the energy efficiency and contribute to the sustainability of the bathroom but in addition can minimize size of the system and cost when contrasted with optimizing individual system in the bathroom (Oye et al., 2020a).

\section{Methodology}

Three modelling processes as shown in table 1 are utilized and the justification for use in this study is the suitability of the model for the proposed bathroom solar water heating system. The bathroom solar water heating is simulated through utilizing Polysun software (Polysun program, 2020).

Table 1. Below shows the modelling process applied in this study

\begin{tabular}{|l|l|}
\hline \multicolumn{2}{|l|}{ The modelling process } \\
\hline $\begin{array}{l}\text { System } \\
\text { description }\end{array}$ & $\begin{array}{l}\text { a system description of the problem situation and the system in which the } \\
\text { problem situation resides }\end{array}$ \\
\hline $\begin{array}{l}\text { Conceptual } \\
\text { model }\end{array}$ & $\begin{array}{l}\text { 'the conceptual model of non-software specific description of the computer } \\
\text { simulation model (that will be or has been developed), describing the } \\
\text { objectives, assumptions, input and output content of the model }\end{array}$ \\
\hline $\begin{array}{l}\text { Computer } \\
\text { model }\end{array}$ & A software specific design and software representation of conceptual model \\
\hline
\end{tabular}

\section{System Description}

The working principle for this study assumes the use of three solar flat plate collector connected in parallel, a backup hot water tank, pre-heating tank, solar heat exchanger, a gas water boiler to serve as auxiliary, circulators, pumps, and mixing devices. The solar flat plate collectors are to be connected in parallel for them to be operating under the same conditions.

The solar radiation from the sun that is absorbed from the solar collector is transformed into heat energy. The collector heat transfer fluid (mixture of glycol and water) circulating in-between the solar heat exchanger and the solar collector transfer the heat energy to the incoming potable water from the solar pre-heating storage tank and at that point the heat fluid returns to the solar collector for the next circulation and so on.

Each time the bathroom system requires hot water, the hot water stored in the in the storage tank is delivered to the outlet point i.e., the shower, tap, basin and the bathtub. The working principle is such that the incoming cold water from the mains first enters the solar preheating tank with equivalent flowrate as the hot water delivered and consequently, the heated hot water in the pre-heated tank flow directly into the storage tank. In the event that the pre-heated water temperature from the solar pre-heating storage tank is above the temperature set point from the water heater, then, the auxiliary water heat would not be activated and as a result, the hot water is delivered directly via the pre-heating tank to the hot water storage tank 


\section{Macrothink}

and then to the bathroom system once the system requires hot water. The auxiliary water heater is only switch on when the hot water temperature is lower that the temperature set point. If the water temperature from the solar pre-heating tank is above the circulator's deactivation set point, the circulation is shut down and no heated fluid is transported in to the solar-preheating tank. In scenario that the demand for hot is very high, or the solar energy is inadequate, the hot water temperature will be below the set point and the auxiliary water heater is activated. Generally, the hot water temperature from the hot water storage tank is higher than the bathroom hot water temperature demand, subsequently, the hot water is mixed with cold water in the mixing device component to obtain the user desired temperature. Also, since to the cold-water system makeup is pre-heated by the solar energy and the system components operations are collectively integrated, much energy savings is expected.

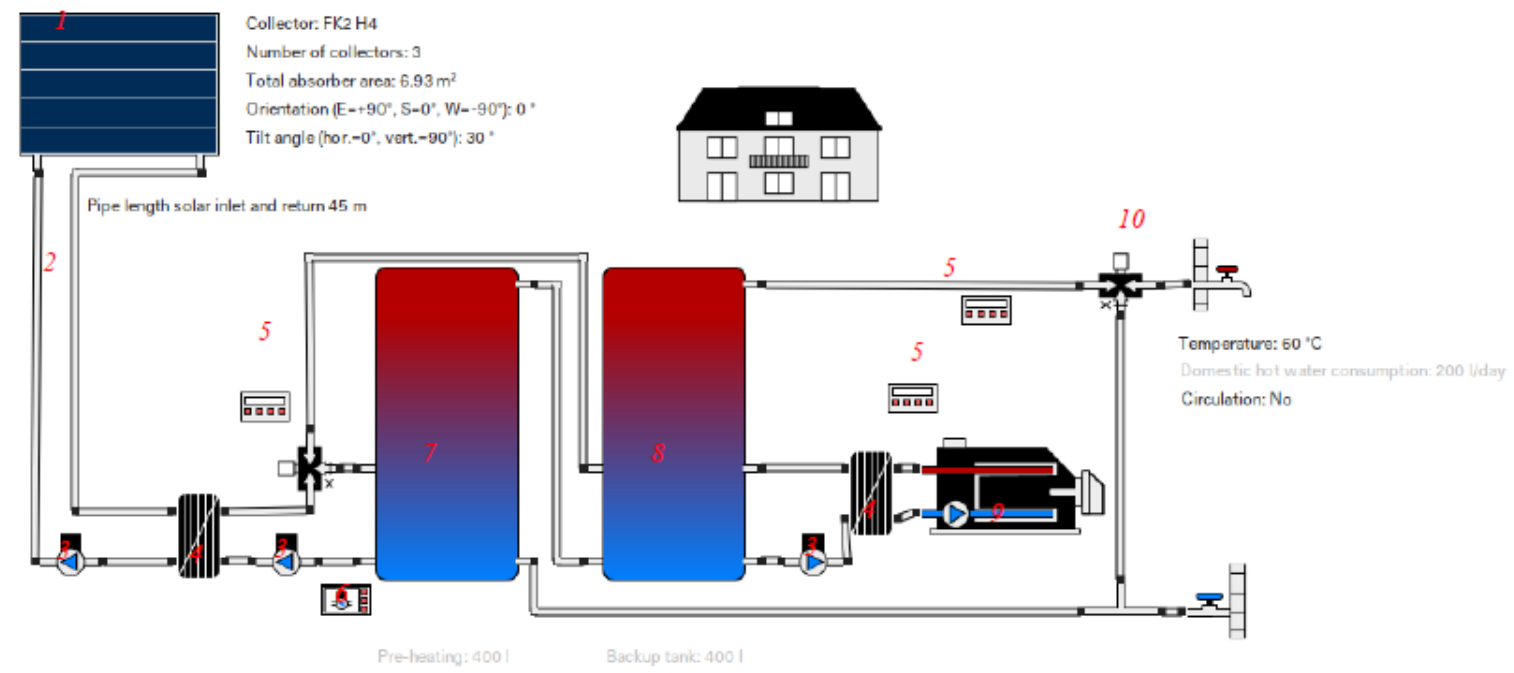

Figure 1. Simplified representation of the solar bathroom unit modelled in Polysun software 1 = Collector, 2 = Connecting pipes, 3 = Solar pump, $4=$ Heat exchanger, $5=$ Auxiliary heating control, $6=$ Variable speed controller, $7=$ Pre-heating tank, $8=$ Backup tank, $9=$ Auxiliary boiler, $10=$ Mixing valve controller

\section{Site Information and Data Collection}

London, United Kingdom, was chosen as the preferred location for this study since it boasts more solar resources than most other region in United Kingdom. The location used in this study is positioned at latitude $51.5^{\circ}$, longitude $-0.17^{\circ}$ and elevation of $36 \mathrm{~m}$. In this study, it is assumed that the home uses a boiler gas as auxiliary hot water heating system and position the storage tank and the pre-heating tank are relative to each other and at a short distance from the collector. This study uses a standard 400-litre pre-heating and backup tank and copper insulated piping.

\subsection{System Modelling and Parameters}

The solar hot water bathroom system modelling is defined utilizing some mathematical 
formulas. The system parameters showing the main components characteristic are expressed as the method of creating the load profile for bathroom hot water.

\subsection{Hot Water Storage Tank and Pre-heating Modelling}

The assumption for modelling the pre-heating and the backup tank is that the heated water in the tanks are thoroughly mixed and has same temperature and can be expressed using time differential equation (Duffie and Willian, 2012). The equation expressing the instantaneous energy balance in the tank as a function of time is expressed by:

$$
m C_{p} \frac{d T_{s}}{d t}=\sum m C_{p}\left(T_{i}-T_{s}\right)+Q_{\text {Source }}-Q_{\text {Loss }}
$$

Where

- $m$ equals the total mass of fluid in the tank (determined by the volume)

- $\quad C p$ equals the heat capacity.

- Ts equals the water temperature in the tank.

- $Q$ is generic energy source terms.

- $m$ equals the water flow rate into the tank.

The model for the backup tank stabilities the temperature with variation of time function of the energy sored in the tank through energy lost to the nearby environment, energy transported from the supplementary water heater as input and the flow of water. The energy build-up from the pre-heating tank is balanced via mainly from solar gain and energy flux via cold water flow and the imperfect tank insulation and can be expressed by

$$
\left(m C_{p}\right) P H T \frac{d T_{P H T}}{d t}=q_{S C^{+}}-q_{L O S S}-m C_{p}\left(T_{P H T}-T_{c}\right)
$$

Where

Tc equals the cold-water temperature make-up

$m$ equals the mass flow rate of the incoming cold-water entering the solar pre-heating water storage tank each time the system demands for hot water.

$T_{P H T}$ equals the water temperature inside the solar pre-heating tank

It is assumed that the pre-heating tank allows enough exchange amid the arriving cold water and the pre-heating tank and subsequent leading to the water out-going at $T_{P H T}$ i.e. even water temperature. The supplementary water heater heating the backup heater is also modelled with same formular as for the solar pre-heating tank. The source of energy is now from the supplementary heating and not from solar gain.

\subsection{Solar Flat Plate Collector}

The flat plate collar collectors are definite kind of heat conversion that absorbs radiation from the sun and then transforms it in energy. Flat plate collectors are one of the most common and 
used type of collectors. The useful energy from the collector that is challenged to the solar pre-heating tank is modelled with the linear equation below from the works of (Duffie and Willian, 2012).

$$
q_{S C}=A_{C} F_{R}(\tau \alpha)_{n} K_{\tau \alpha} G_{T}-A_{c} F_{R} U_{L}\left(T_{P H T}-T_{a}\right)
$$

Where

- $\quad I_{T}$ equals the global solar irradiation on a tilted surface

- $G_{T}$ equals the global incident solar radiation $\left(\mathrm{W} / \mathrm{m}^{2}\right)$

$$
G_{T}=I_{T} * \frac{1}{60}
$$

- $(\tau \alpha)_{n}{ }^{\prime}$ is the transmittance-absorptance product at normal incidence for a flat plate solar collector.

\subsection{Solar Heat Exchanger Modelling}

The solar energy that is accumulated is channeled to the solar pre-heating tank using heat exchanger. Figure 2 below shows a typical counter current heat exchanger with outlet temperatures and inlet temperatures, rates of capacitance of fluid heat transfer and the circulating hot water in the bathroom.

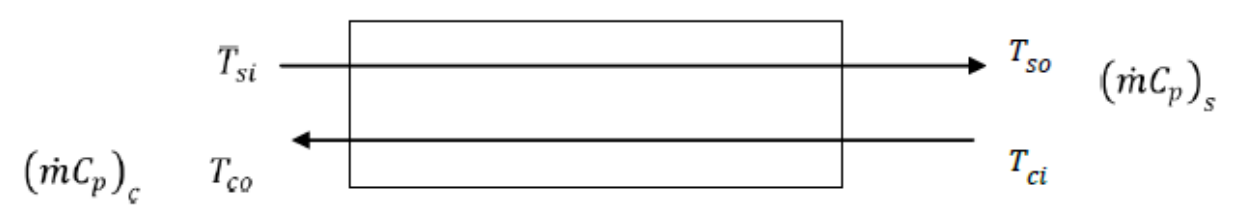

Figure 2. Schematic of a counter-flow heat exchanger (Duffie and William 2012)

The below equation 5 describes the effects of the heat exchanger using the effectiveness that can be determined by

$$
\varepsilon=\left\{\begin{array}{c}
\frac{1-e^{-N T U\left(1-C^{*}\right)}}{1-C^{*-N T U\left(1-C^{*}\right)}} \quad \text { if } C^{*} \neq 1 \\
\frac{N T U}{1+N T U} \quad \text { if } C^{*}=1
\end{array}\right.
$$

Where

NTU equals the number of transfer units and its represented as:

$$
\frac{U A}{\left(m C_{P}\right)_{\min }}
$$

Where

$m C p_{s}$ is heat capacitance $(\mathrm{W} / \mathrm{K})$ of the circulating bathroom hot water 
$m C p_{c}$ is the fluid heat transfer capacitance $(\mathrm{W} / \mathrm{K})$ of the solar collector

\subsection{Auxiliary Heating}

The overall quantity of heating energy provided to the bathroom hot water system by the auxiliary water heater is expressed by:

$$
Q_{H P}=\int\left(C O P X W_{H P}\right)
$$

Where

- $W_{H P}$ equals the power consumed by the heat pump's compressor

- $Q_{H P}$ equals the overall heating energy supplied by the heat pump

The COP is the auxiliary heating performance coefficient and its reliant on the condensing temperature and condenser inlet. The condenser inlet's temperature is assumed to be equivalent to the solar pre-heating tank temperature; consequently, the value is a time function, and this makes COP vary in time.

\section{Simulation Assumptions}

The performance of each bathroom hot water system component is be simulated. The simulation is completed using one-hour time-step. The component parameter and load profile assumptions are well defined below.

\subsection{Flat Collector}

The technique employed in this study assumes three solar flat plate collectors as a supplementary advantage of higher quantity of absorbed radiation from the sun and subsequently allows greater transfer of heat to flow via the internal pipes of the collector. The collector pipes are assumed to be coated with copper to reduce the amount of heat lost to the environment. The collector's fluid volume is assumed to be two bars.

The total number of collectors employed is consistent with the recommendation from industry for household solar hot water consumption more than 250 1/day (Solar collector, 2018). The total aperture area of the three solar collectors is $7.53 \mathrm{~m}^{2}$. They are assumed to be arrayed in a parallel arrangement so that each of them functions under the matching conditions.

\subsection{Solar Heat Exchanger}

Solar heat exchanger basically the process how the solar energy absorbed from the collector is transported to the bathroom hot water system. The type of heat exchanger this study assumes is the counter flow heat exchanger with overall heat transfer value of $260 \mathrm{~W} / \mathrm{K}$ (Duffie and William 2012). The circulating bathroom hot water from the pre-heating tank is assumed to have equal water temperature as the tater in the tank. The effectiveness $\varepsilon$ solar heat exchanger is a calculated value which is 0.90 (Duffie and William 2012).

\subsection{Auxiliary System}

The water heater assumed in this study is manufactured by ETECH with heating capacity of 
$310 \mathrm{~kW}$ and cooling capacity of $5 \mathrm{~kW}$. The highest supplied bathroom hot water temperature is $60^{\circ} \mathrm{C}$ and the working rage for the ambient temperature for the water heat is between $5^{\circ} \mathrm{C}$ and $40^{\circ} \mathrm{C}$. The chosen ambient temperature range is $18{ }^{\circ} \mathrm{C}$ and assumed to be installed in the household residence. The heater gets switched on if water temperature in either the pre-heating tank or the storage tank is lower than the user set point.

\subsection{Solar Pre-heating Tank}

The solar pre-heating tank is considered to have equal physical size and heat insulating as the storage hot water tank. The initial temperature for the preheating tank for the summer months and winter months are assumed to be $60{ }^{\circ} \mathrm{C}$ and $30{ }^{\circ} \mathrm{C}$ respectively.

\subsection{Hot Water Storage Tank}

The use of pre-heating and storage tank for heat energy storage is largely more efficient. The goal is to store adequate hot water in the tank and via the supply system and to the end use. The water consumption profile mostly determines the sizing of the tank volume. The energy storage capacity of the storage and pre-heating tank are significant for water supply efficiency in the bathroom. Moreover, the tank should be able to store sufficient water to satisfy the daily needs. The demand of water and its consumption pattern i.e., if household residents use more water in some particular months or for a specific occasion should be considered when sizing the tank. In determining the suitable tank size, the consideration of monthly and yearly values per person or per family as the volume varies is vital.

For this study, the tank size is determined by the amount of utilized hot water utilized and household's size. A tank that is designed poorly will lose huge energy due to high flue temperatures. A good tank design like a boiler will extract more heat energy and transfer it to the water and consequently, resulting in 0.9 recovery efficiency or higher.

\subsection{Pipe Data}

Pipe connects the water heating components and the water tanks to the fixtures. Most pipe connections are designed to be indoors for conventional water heating system. For a solar water heating system, some pipes that connects the flat plate collector and the external heat exchanger is located outdoor. The pipe networks are also vital to the system efficiency due to potential thermal loss and mass. In this research study, the impact of piping networks and characteristic are accounted for in a direct method.

The indoor total pipe length between the flat plate connector and the pre-heating tank is assumed to be 10 meters while the outdoor total pipe length is assumed to be 20 meters. The diameter of the indoor and outdoor are assumed to be $25 \mathrm{~mm}$. The convection coefficient of air on the external surface of the pipes is $10 \mathrm{~W} / \mathrm{m}^{2} \mathrm{~K}$. The heat insulation of the pipe is $25 \mathrm{~mm}$ thick, and the equivalent thermal conductivity is $0.02 \mathrm{~W} / \mathrm{m} \mathrm{K}$. The hot water temperature in the pipe is assumed to be constant at each location in the pipe.

\subsection{Hot Water Draw Profile}

Daily hot water draws pattern and profiles have been studied for many decades. Authors like 


\section{Macrothink}

Stevenson (1983), Perlman and mills (1985), Parker (2003), Energy Saving Trust (2013) have all highlighted that hot water draw patterns shows high daily peak in the morning and evening, the amount of water consumed is a function of number and types of occupant and concluded that based on hot water consumption for a typical family of four, between 240 and 250 liters of daily consumption will satisfy the user demands.

The standardized bathroom daily hot water profiles utilized in this study is taken from Energy saving Trust (2013) and DEFRA (2008). The average daily hot water draws for four person's consumption pattern is 250 liters with the end use of temperature of $60^{\circ} \mathrm{C}$.

\section{Integrated Energy performance Analysis of the System Component}

The performance of the solar hot water systems components is mostly evaluated using system performance and energy factor. These are computed by via a standardized method. Some of the energy performance metrics employed in this study quantifies and compares the effects of using diverse energy saving technologies for bathroom hot water heating.

The purpose is to evaluate the effect of the main components of the system from the holistic performance point of view. The energy performance indices evaluated in this study are:

1) energy collected,

2) energy delivered and supply pipe losses,

3) solar fraction,

4) collector efficiency

5) system efficiency

\subsection{Delivered Energy}

This is the energy delivered by the solar hot water system in the bathroom. The energy delivered is contingent on the amount of the heat water used daily, the temperature of the incoming potable water and the resultant hot water temperature delivered. The equation is expressed by:

$$
Q_{D E L V D}=\int(M C p) s(T s-T c) d t
$$

Where

$\left(T_{s}-T_{c}\right)$ is the temperature change between delivered hot water and the potable cold water.

$m$ is the mass flow of the delivered hot water from the backup tank and can be additional expressed by

$$
m=\rho * \sum_{i}^{n} v_{i}
$$

$\rho$ equals the water density $\left(998 \mathrm{~kg} / \mathrm{m}^{3}\right)$

$\sum_{i}^{n}=1 V i$ equals the instant whole volume flow rate of the hot water delivered to , $n^{\text {ee }}$ plumbing fixtures.

\subsection{Collected Solar Energy}


The collected solar energy $Q_{S C}(\mathrm{kWh})$ is the total solar energy collected by a solar collector over a given period, $\tau$. It is defined as:

$$
Q_{S C} \int_{0}^{\tau}(q s c) d t
$$

Where

$\mathrm{q}_{\mathrm{sc}}$ equals the instantaneous heat flows collected by a solar collector.

\subsection{Total Heating Energy}

This amounts to the total energy produced by the bathroom system components and can be defined as the addition of the energy delivered by the flat plate collector, energy delivered by the auxiliary heater and the heat exchanger. This can be expressed by the below equation.

$$
Q_{T H E}=Q_{S C}+Q_{H E}+Q_{\mathrm{WH}}
$$

Where,

$Q_{S C}, Q_{H \mathrm{E}}$, and $Q_{W H}$ are energy $(\mathrm{kWh})$ produced from the flat plate collector, heat exchanger water, and the auxiliary water heater respectively.

\subsection{Delivered Solar Heating Energy}

This is principally the total amount of solar hot water energy supplied to the bathroom system that is used up daily. Moreover, few amounts of this energy are being replaced by the conventional energy. This amount of energy is controlled by the change in the enthalpy of the hot water channeled through the pre-heating tank. hot water via the pre-heating tank and the supplied water temperature of the pre-heated water is $T_{P H T}$ while the temperature of the potable cold water make up is Tc. The governing equation can be expressed by

$$
Q_{S C . D E L V D}=\int_{0}^{1 d a y} m_{P H T} C_{p}\left(T_{P H T}-T_{c}\right) d t
$$

\subsection{Carbon Emission}

The total carbon emission yield from the supplementary heating system and the system components can be expressed by:

$$
\mathrm{CO}_{2}=\mathrm{ICO}_{2} \mathrm{We}
$$

Where,

$\mathrm{ICO}_{2}$ signifies the intensity emission of the supplementary source of energy.

The carbon emission is a vital pointer to assess if a specific system is environmentally sustainable (Duffie \& William 2012).

\subsection{Solar Fraction}

The solar fraction metric represents the fraction if the whole energy supplied by the solar 
collector each day. Moreover, it stipulates the specific amount of the heating energy supplied to the system that is from the flat plate collector. It can be expressed by

$$
F_{S}=\frac{Q_{S C}}{Q_{T H E}}
$$

Where,

$F s$ is the solar fraction,

$Q_{T H E}$ is the daily total heating energy flow into bathroom water heating system.

$Q_{S C}$ is the amount of solar energy collected in one day.

\section{Result and Discussion}

The energy and environmental performance indices investigated in this study are:

1) Solar Fraction

2) Energy supply or yield

3) Total energy consumption of the system

4) Primary Energy Savings,

5) System performance and Efficiency

6) Reduction of $\mathrm{CO} 2$ emissions

\subsection{Performance Analysis of the Solar Fraction (Monthly and Annual)}

In table 2 below, the average outdoor temperature and global irradiance time series are list over a one-year period. The annual average direct irradiance and diffuse irradiance for London are $2117 \mathrm{kWh} / \mathrm{m} 2$ and $2384 \mathrm{kWh} / \mathrm{m} 2$ respectively. The definition of seasons used in this study are according to fixed dates at even intervals of months as shown in Table 2. The highest amount of solar radiation is received in summer (April to October), whereas in winter (December to February) there is the least amount. Therefore, according to the measured irradiance figures, the solar collector's energy yield is expected to be larger in spring to summer months than in any of the other season. Consequently, a lower energy yield is expected in winter than in any other season.

On days where the solar panel is unable to extract enough heat energy due to lack of solar irradiation, the boiler is used as auxiliary in providing provide energy to heat up the water in tank. The design shows that the system is capable of more than 95\% performance for 5 months, from May to September. This correlates to the availability of solar irradiation during the summer period. Based on the result, the energy deficit is $493.2 \mathrm{kWh}$. This is between the months of November to February, where during winter the solar irradiation is low. During this period, the gas boiler is utilized more.

A total of $4688.596 \mathrm{kWh}$ energy saving is possible. The reduction in $\mathrm{CO} 2$ emission at 1.398 tons annually is also very high.

The solar thermal that is generated into the system for the energy consumption for the entire bathroom unit is $10,799 \mathrm{kWh}$. The solar system provides $65 \%$ of the required power for the 
bathroom unit, in which $80 \%$ is used for hot water consumption. The total heat loss to the surrounding of the bathroom is around $15 \%$ of the supplied thermal energy.

Table 2. The average outdoor temperature and global irradiance

\begin{tabular}{|l|l|l|l|l|}
\hline Month & $\begin{array}{l}\text { Average outdoor } \\
\text { temperature } /{ }^{\circ} \mathrm{C}\end{array}$ & $\begin{array}{l}\text { Average direct } \\
\text { irradiance/ } \mathrm{kW}\end{array}$ & $\begin{array}{l}\text { average scattering } \\
\text { irradiation/ kWh }\end{array}$ & $\begin{array}{l}\text { average global } \\
\text { irradiance/kWh }\end{array}$ \\
\hline January & 6.5 & 147 & 102 & 249 \\
\hline February & 6.7 & 151 & 173 & 324 \\
\hline March & 8.4 & 259 & 303 & 562 \\
\hline April & 10.9 & 417 & 364 & 781 \\
\hline May & 14.1 & 452 & 502 & 955 \\
\hline June & 17.1 & 368 & 543 & 912 \\
\hline July & 19 & 450 & 494 & 945 \\
\hline August & 18.8 & 466 & 451 & 917 \\
\hline September & 16.2 & 379 & 327 & 706 \\
\hline October & 13 & 298 & 219 & 517 \\
\hline November & 9.3 & 179 & 119 & 298 \\
\hline December & 7 & 103 & 83.3 & 188 \\
\hline
\end{tabular}

Irradiation onto collector area

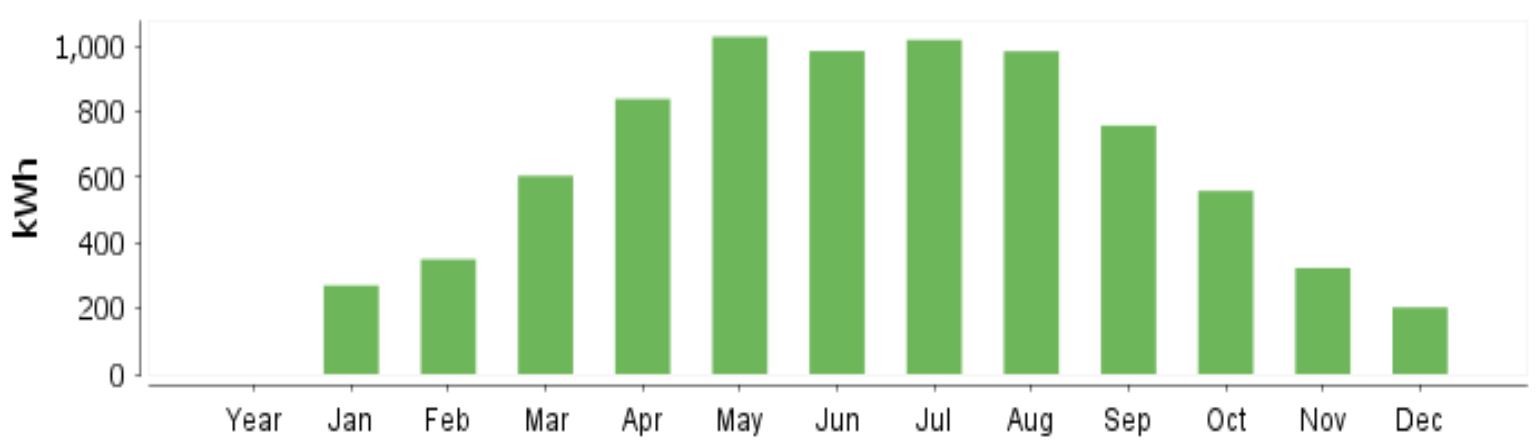

Figure 3. Radiation into the solar collector

Solar fraction: fraction of irradiation in the collector plane

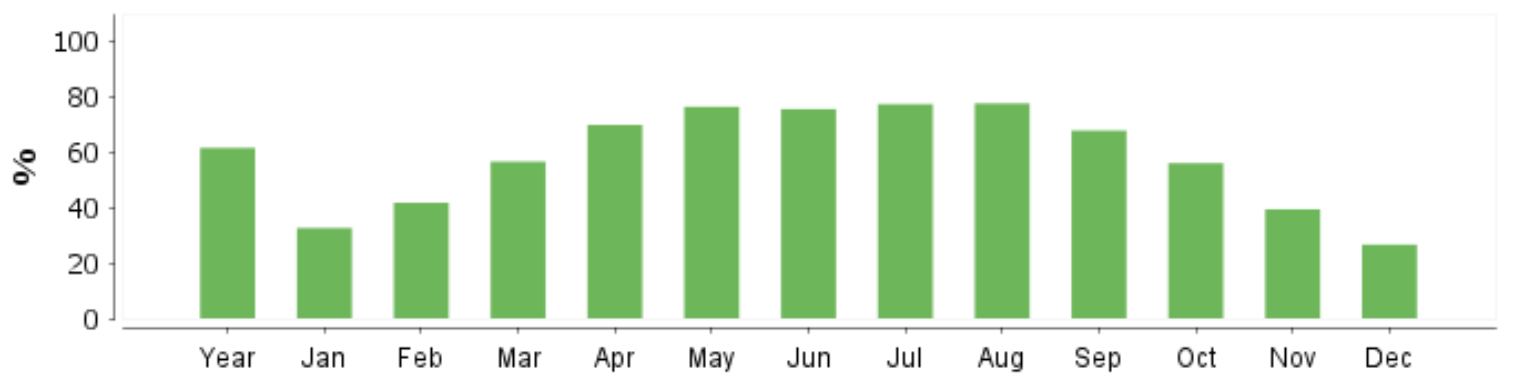

Figure 4. Solar fraction of irradiation in the collector plane 


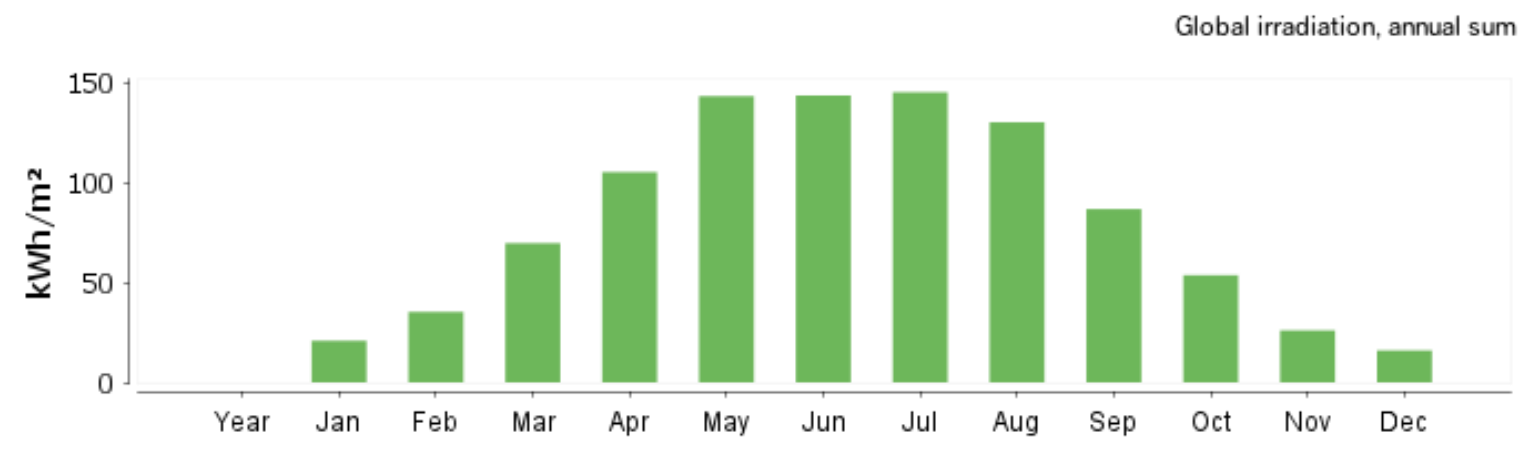

Figure 5. Global irradiation

The monthly solar fractions obtained by simulation for the bathroom configurations of the solar hot water heating system are shown on Fig. 4. The peak of efficiency of the solar system is clearly reached between April and October. In May to August, where the model predicts the maximal efficiency. Monthly solar fractions reach values from $20 \%$ for the least efficient configuration to $65 \%$ for the most efficient one. These figures are in the range or above the estimation of SPF for solar pre-heating (25\%), discrepancies are due to the different components embedded in systems. The solar fraction increases markedly in spring and decreases markedly in autumn; variations of more than $10 \%$ from one month to another are expected. At the same time the difference between configurations becomes evident: it decreases in autumn and grows in spring. Still, the pre-heating can provide an appreciable amount of energy, which (depending on the system configuration) remains in the range of 20 to $30 \%$ minimum in December to January. The difference between January's results and December's ones is weak. In any case, the solar pre-heating system will provide a small, if not negligible, part of energy needed during these months. These results are coherent with the estimated evolution of solar insolation in Bristol given by the Solar Electricity Handbook, 2016. The model gives then coherent results relatively to what could have been expected.

\subsection{Performance Analysis for Energy Supply and Total Energy Consumption}

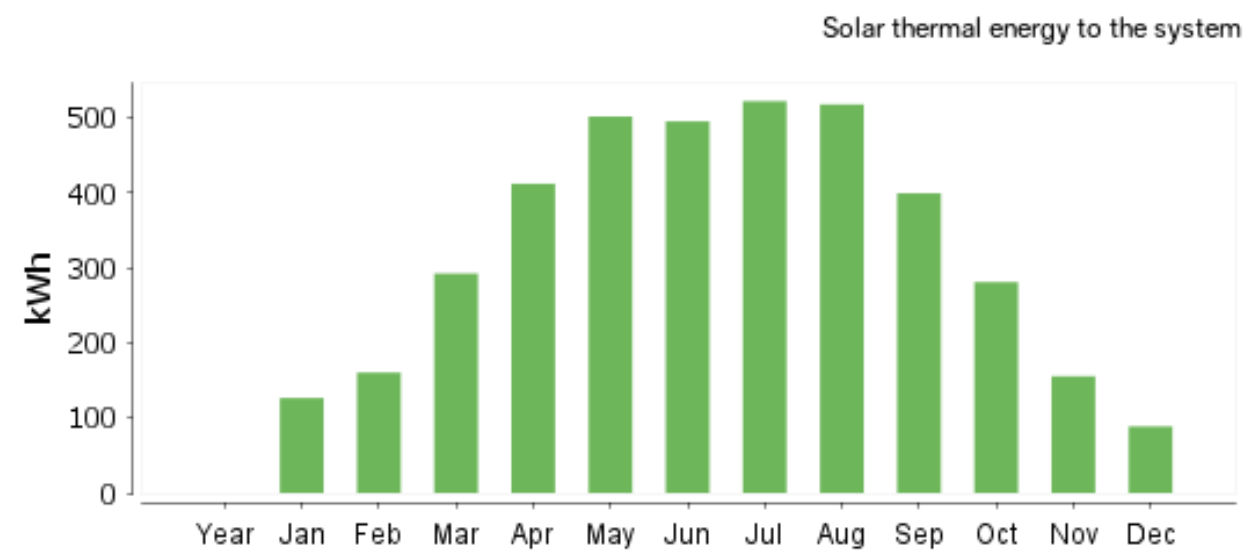

Figure 6. Solar thermal energy to the system 
Total energy consumption

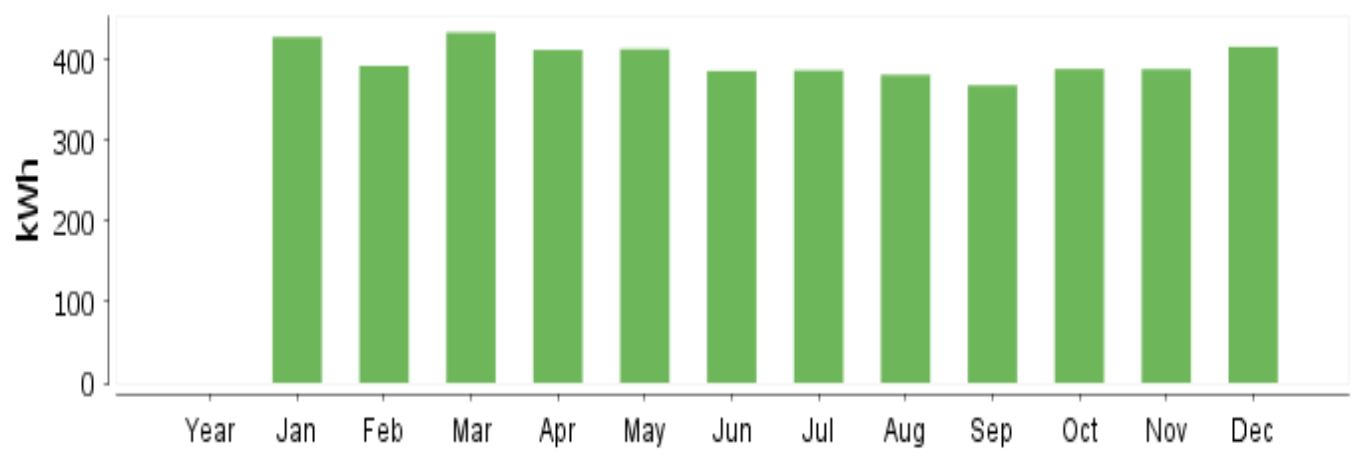

Figure 7. Total energy consumption

Consequently, Figure 6 and Figure 7 clarifies the outcome of the energy production of solar thermal yield to the bathroom system with the auxiliary electricity consumption from the consumption profiles and the electricity consumption of the thermal components. The monthly solar energy and the load results for the bathroom hot water system were analyzed to verify that the model output energy values are reasonable as total energy demand was covered. Figure 7 shows the monthly total load and the collected useful solar energy for a hot water system in London house with $7.5 \mathrm{~m} 2$ collector area and a 250 litter per day DHW draw.

For the bathroom hot water usage to stay in the range of comfort temperature, the control must be able to switch sharply between high and low temperatures to maintain optimum performance for the system i.e., the system should self-regulate itself if the user set temperature is below or above the output of the system. Correspondingly, the required power is used up to operate the fluid pumps and auxiliary boiler. In the spring to summer season (April - October), the solar flat plate collector produces enough useful energy through to the system with little auxiliary heating from the boiler. As a result, the integrated solar bathroom system can perhaps completely provide enough energy independently with overall annual solar CO2 savings of $1,398 \mathrm{~kg}$ as presented in Figure 9. Additionally, the remaining produced energy may perhaps be retained for future use. This suggests that optimization of top possibilities is concealed in the accessibility of the solar integrated bathroom systems together with the consumption of small electric power for auxiliary hot water production.

\subsubsection{Energy Supply or Yield}

The result shows that, the total solar annual energy supplied to the bathroom system is 4,878 $\mathrm{kWh}$. Energy supplied during the winter months is low as it can only provide $20 \%$ of the energy required, this means the auxiliary heating system works more during winter. Consequently, the auxiliary heating system is optimized to increase the efficiency of operation and to save significant amount of energy especially during the winter months. In the spring to summer season (April - October), enough useful energy is supplied to the bathroom system with little auxiliary heating from the boiler for energy demand to be covered. 


\section{Macrothink

\subsubsection{Total Energy Consumption of the System}

The result shows that, the total annual energy consumed by the system is $8,675 \mathrm{kWh}$. This includes solar energy consumed, auxiliary energy consumed, and energy required to power other components for operation e.g., pumps, boiler, heat exchanger. The efficiency of the consumption is determined by the energy balance in the tank. The energy balance in the tanks are negative during the winter months due to energy lost to the environment. As a result, the system will consume more energy to make up for the lost energy.

\subsection{Performance Analysis Energy Savings, $\mathrm{CO}_{2}$ Savings and System Performance}

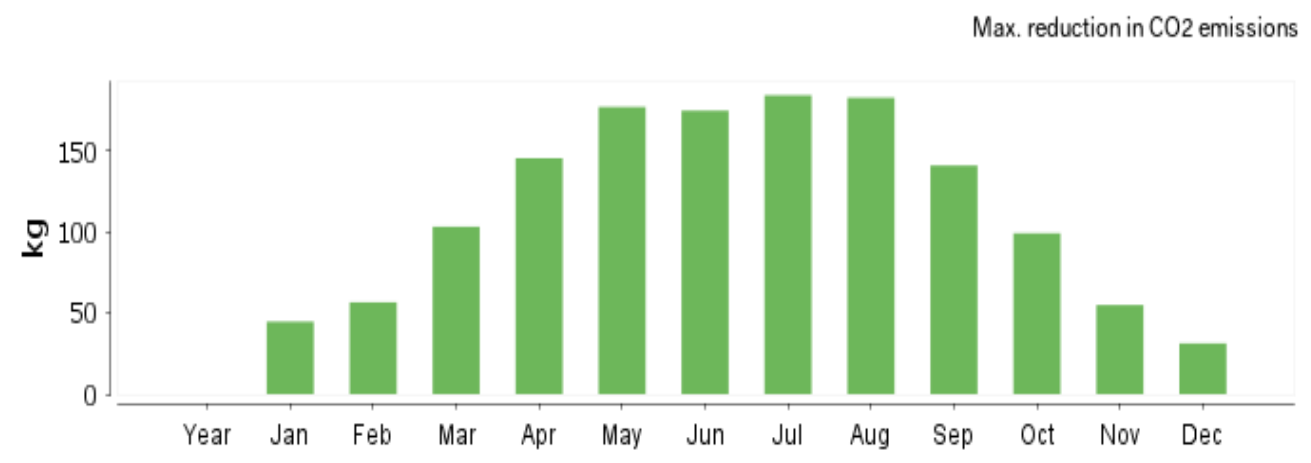

Figure 8. Maximum reduction of carbon emission

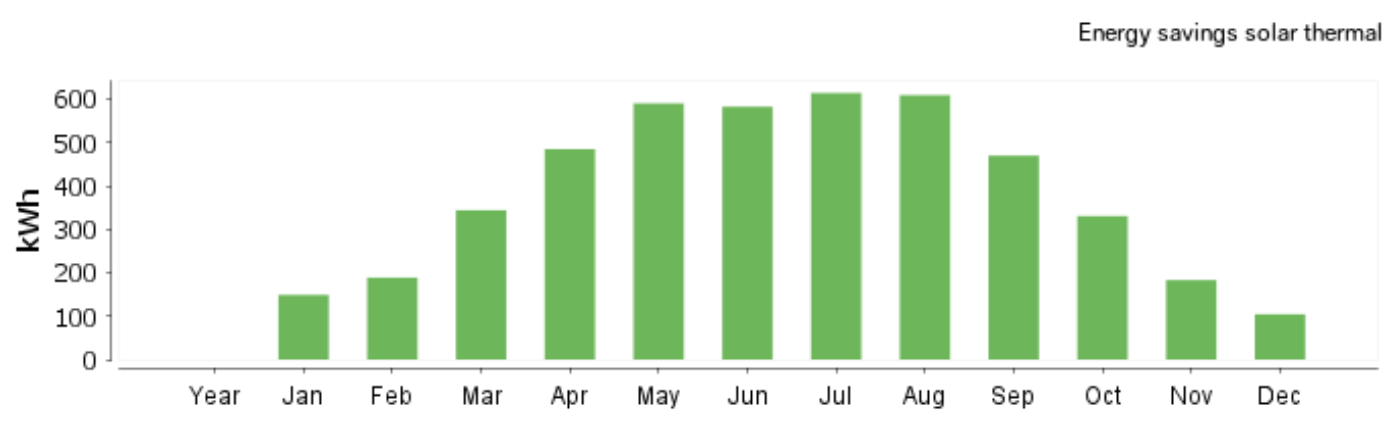

Figure 9. Energy savings solar thermal



Figure 10. System performance 
Figures 8 and 9 show that there is significant energy and carbon emission savings, this because solar thermal systems will provide more hot water during the summer than during the winter. This means that an auxiliary heat source will still be required to heat the water during the winter months. However, solar thermal systems are still able to save between 50\% and 60\% of the energy that would have been required annually to heat up the hot water using conventional energy sources, such as gas or electric alone.

Similarly, during the winter months, the solar collector is not able to completely cover the hot water consumption i.e., the total energy consumption of the system and domestic hot water loads of the heating. So, there is a necessity for an auxiliary heat basis. The auxiliary gas heater is utilized in this situation for heat-up whenever the system is unable to meet up the set hot water temperature required.

The auxiliary heat provided by the heating system is transmitted to the backup tank storage for preheating of bathroom hot water. This operation makes energy usage to be efficient and subsequently enhances the performance of the overall system as well by making sure the system only uses the required hot water needed in the bathroom.

Accordingly, the auxiliary boiler is optimized to increase the efficiency of operation and to save significant amount of energy and $\mathrm{CO} 2$ during operation especially during the winter months. The simulation has shown that a solar collector coupled with integrated bathroom component can not only yield high energy savings but can also achieve an appreciable annual reduction of $\mathrm{CO} 2$ emissions.

The energy balance in the tanks is negative during the winter months due to energy lost to the environment. As a result, energy is added to the tank by the auxiliary boiler to supply energy through the external heat exchanger. During this time, little energy storage in the tank occurs. In contrast, during the summer months, more energy is being delivered to the tank by solar collector through the heat exchanger and that energy is being stored in the tank. During this period, the tank losses and auxiliary heating are at minimum.

Also, additional energy savings is expected since the system component has very low electricity consumption i.e., the modelled auxiliary gas boiler power is $10 \mathrm{~kW}$ with internal electricity consumption less than $500 \mathrm{~W}$. Energy savings related to the solar thermal contribution are observed since heat energy is driven by the auxiliary boiler when heating power is required by the system component and the solar radiation is not enough.

\subsubsection{Energy Savings}

This indicates the percentage of the energy saved in comparison to a conventional system where the same energy consumptions must be covered, and no renewable energy sources are used. After optimizing the system, the model results shows that however, solar thermal systems are still able to save between $50 \%$ and $60 \%$ of the energy that would have been required annually to heat up the hot water using conventional energy sources, such as gas or electric alone. Most of the savings occurred during the summer months while there was maximum $20 \%$ energy savings during the winter months. 


\subsubsection{Reduction of CO2 Emissions}

After optimizing the system, the integrated solar bathroom system completely provided enough energy independently with overall annual solar CO2 savings of $1,398 \mathrm{~kg}$. This signifies that the energy usage is efficient which enhances the performance of the overall system by making sure the system only uses the required hot water needed in the bathroom. This is one of the key benefits of system optimizing as opposed to individual component optimization.

\subsubsection{System Performance and Efficiency}

The system performance is a function of the solar fraction, energy supply and savings and the efficiency of the integrated interaction of the system component.

The system performance also points out how much energy is consumed per thermal energy distributed into the system. It takes into consideration not only the internal energy consumption of the main components such as heat exchanger and tank storage but all the auxiliaries and distribution pumps as well.

How efficient the system components interact together to generate effective outcome is summed up into single value. The higher the value the better the performance of the system. Figure 10 has demonstrated that there is generally better performance of the system during the summer months compared to the winter months. Although even during the winter months, the performance is still good. The average year performance of the system is 0.95 .

\section{Parametric Study}

The behavior of a solar thermal system depends on many parameters related to its main components, such as collector inclination angle, collector area, pipe length, tank volume, auxiliary heating, and controller settings etc. In this chapter, a parametric study is conducted on the Polysun model, which from now on will be referred to as the reference system, in which the effect of various design- and operation parameters on system performance is examined. The analysis was focused on control strategies for auxiliary heating, hot water load profiles and different climatic conditions. The solar fraction was used to compare the relative performances of the system configurations. This expression compares the annual energy use of a solar domestic hot water system with the reference bathroom solar hot water system model presented in this chapter of this study.

To find the improved value of each parameter, or, if possible, the optimum value, only one parameter was changed at a time while the other parameters were kept at their initial settings.

\subsection{Control Strategies for Auxiliary Heating}

The switch-on temperature for auxiliary heating is set to $60^{\circ} \mathrm{C}$ in the reference system, which is much higher than the draw-off temperature setting of $40-50^{\circ} \mathrm{C}$. This variation influences not only the comfort but also the energy performance (reference). To study the impact of different switch-on settings for the auxiliary heating, the model was simulated for selected switch-on temperatures ranging from $40^{\circ} \mathrm{C}$ to $75^{\circ} \mathrm{C}$. The impact of various switch-on 


\section{Macrothink}

temperatures on the amount of solar and auxiliary energy supplied to the tank temperature was constantly set to be $2^{\circ} \mathrm{C}$ higher than the switch-on temperature. The simulated annual solar fraction and the corresponding specific delivered energy are presented in Figure 11.

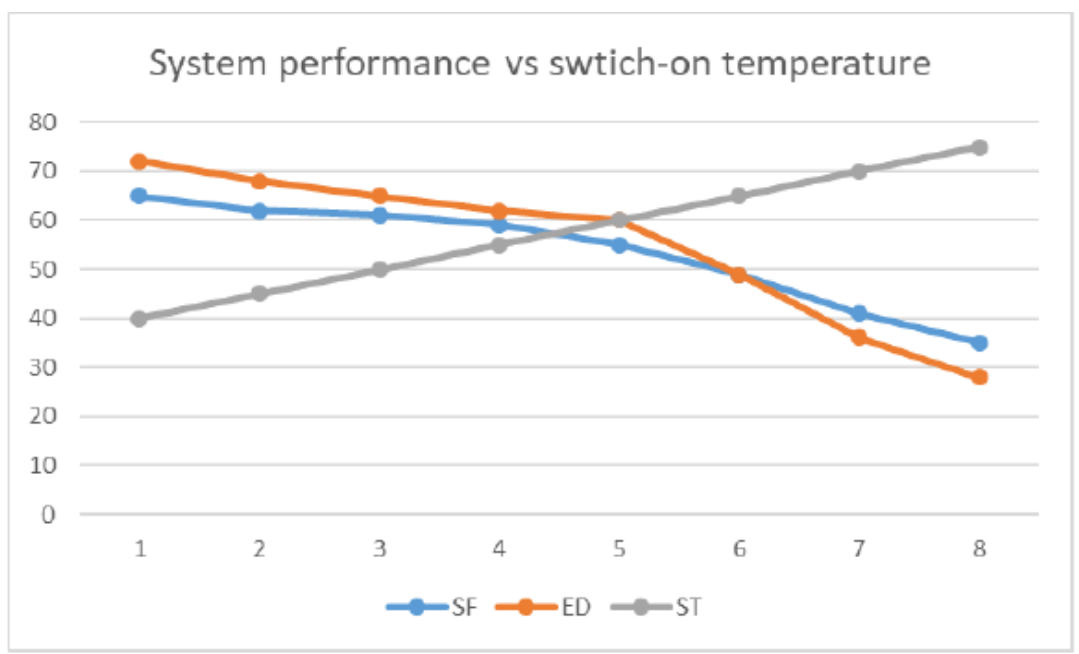

Figure 11. System performance vs switch-on temperatures

SF- Solar fraction, ED- Energy delivered, ST- Switch-on temperatures

\subsection{Analysis from Graph}

As depicted in the graph, a higher switch-on temperature results in a diminishing annual specific delivered energy to the system, as well as a considerably lower annual solar fraction. This is because of the significant increase in necessary auxiliary energy that is required to compensate for the increased energy demand for after-heating. Furthermore, a higher temperature setting reduces the utilization of solar energy.

\subsection{Parameters Related to the User}

In this section, the impact of selected user-related parameters is studied. Doing so may make it easier to reveal important design features that can contribute to the evaluation of other solar systems, located in the other passive households in the United Kingdom. These solar systems are similar to that of the reference system but may be subject to other heat demands and consumption habits.

\subsection{Different Bathroom Hot-water Load Profiles}

Since the load profile can influence the system performance, five different measured bathroom hot load profiles were analyzed. According to Energy Saving Trust (2010), the following categorization of daily hot water consumption was applied:

1) Low consumption: 30-55 1/day per person

2) Normal consumption: 60-75 1/day per person

3) High consumption: 80-100 1/day per person 


\section{Macrothink}

In a domestic household, it is rational to assume that the number of residents may vary from only one person up to a family of five, which causes significant variations in the total hot water consumption. Based on the three consumption groups identified above, the approximated hot consumption (1/day) of a dwelling is roughly estimated according to the number of inhabitants in Table 5.2

Table 3. Different bathroom hot-water Load Profiles

\begin{tabular}{|l|l|l|l|}
\hline No of occupants & $\begin{array}{l}\text { Low consumption } \\
\text { 1/day }\end{array}$ & $\begin{array}{l}\text { Normal consumption } \\
\text { 1/day }\end{array}$ & $\begin{array}{l}\text { High consumption } \\
\text { 1/day }\end{array}$ \\
\hline 1 & $40-55$ & $60-75$ & $80-100$ \\
\hline 2 & $60-70$ & $80-120$ & $150-180$ \\
\hline 3 & $70-100$ & $100-150$ & $190-250$ \\
\hline 4 & $110-140$ & $180-250$ & $260-300$ \\
\hline 5 & $150-190$ & $200-290$ & $300-350$ \\
\hline
\end{tabular}

To investigate how the annual domestic hot water consumption affects the performance of a solar thermal system, the model was simulated for average daily consumptions ranging from as little as 40 1/day (1-person, low consumption) to 250 1/day (3 persons, high consumption). The results are presented in Figure 5.12.

\subsubsection{Analysis from Graph}

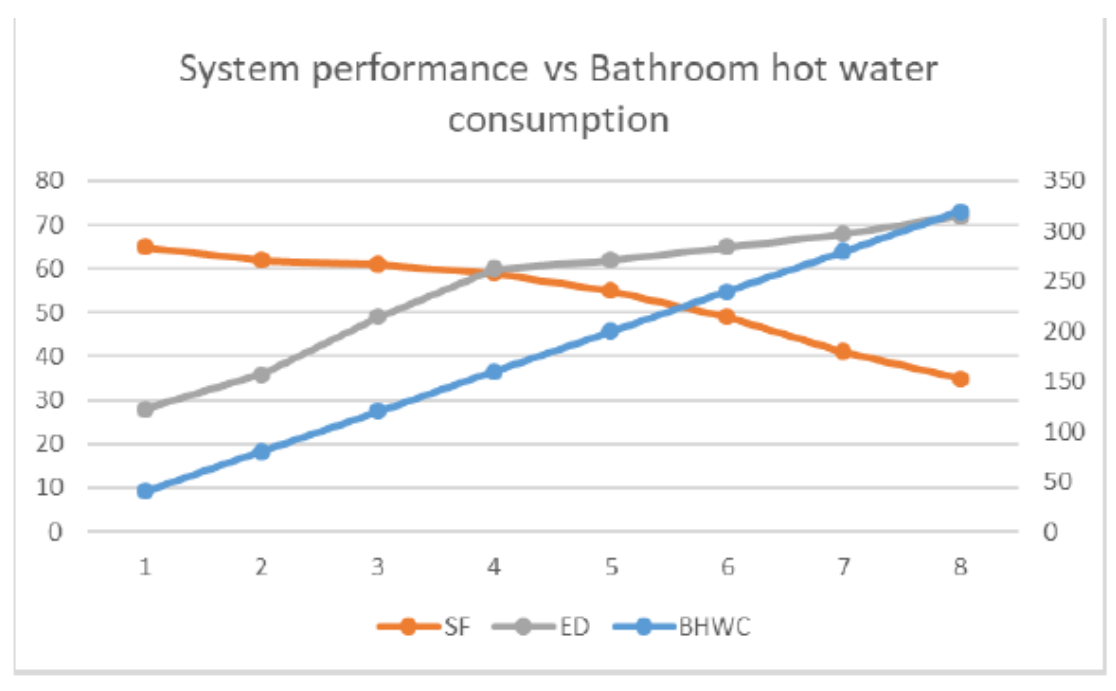

Figure 12. System performance vs hot water consumption

SF- Solar fraction, ED- Energy delivered, BHWC- Bathroom hot water consumption.

The results in Figure 12 suggest that an identical solar thermal heating system in the London households' study may achieve a higher solar fraction if the hot water consumption is lower than that of the reference system. However, this is not in itself a guarantee of higher 
performance; the solar fraction decreases slightly along with a higher consumption only up to an average daily consumption of approximately 250 1/day, where it reaches a maximum and starts decreasing sharply. This is because the auxiliary energy consumption becomes more dominating.

\subsection{Analysis of Average Daily Consumption vs Annual Solar and Electric Consumption}

Interpreting from Figure 12 suggest that, to maintain a specific performance resulting to the user consuming the same amount of hot water in the bathroom every day throughout the year is not realistic, the results still provide an indication of how a change in bathroom hot water consumption affects the system performance. From the reference system, an average daily consumption of $250 \mathrm{l} /$ day corresponds to an annual consumption of $4,804 \mathrm{kWh}$ and falls within the range of a household of three to four people with normal consumption habits (based on the values in Table 4).

\subsection{Analysis of Different Climatic Locations}

The distribution of the solar radiation throughout the year in different climatic locations influences not only the annual solar fraction, but also the system performance. The annual energy performance of the designed systems was evaluated under different climates, that is, in London climate and in two other cities i.e., Aberdeen (United Kingdom) and Rome (Italy). The three cities London (reference system), Aberdeen and Rome selected can also represent most of the similar region climate in the United Kingdom and Europe. The modelling of the annual performance was performed based on the hourly weather data of individual cities in Polysun. All cities were assumed to have the same load profile as in London and thereby creating a common basis for comparison.

Table 4. Analysis of Different Climatic locations

\begin{tabular}{|l|l|l|l|l|}
\hline System & Unit & London & Aberdeen & Rome \\
\hline Collector area & $\mathrm{m}^{2}$ & 7.5 & 7.5 & 7.5 \\
\hline Solar fraction total & $\%$ & 65 & 44.6 & 83 \\
\hline System Performance & - & 0.95 & 0.72 & 1.74 \\
\hline Total solar annual field yield & $\mathrm{kWh}$ & 3952 & 3351.4 & 6107.3 \\
\hline Total energy consumption & $\mathrm{kWh}$ & 4804 & 4116 & 3720 \\
\hline Primary energy factor & - & 1.17 & 1.55 & 0.64 \\
\hline Comfort demand & - & $\begin{array}{l}\text { Energy demand } \\
\text { covered }\end{array}$ & $\begin{array}{l}\text { Energy demand } \\
\text { covered }\end{array}$ & $\begin{array}{l}\text { Energy demand } \\
\text { covered }\end{array}$ \\
\hline Energy savings & $\mathrm{kWh}$ & 4649 & 3942.9 & 7185.1 \\
\hline CO2 savings & $\mathrm{Kg}$ & 1398 & 1186 & 2160 \\
\hline
\end{tabular}

Table 5. Meteorological data for Aberdeen, Rome and Reference system

\begin{tabular}{|l|l|l|l|}
\hline Meteorological data-Overview & Reference system & Aberdeen & Rome \\
\hline Average outdoor temperature & $12.3^{\circ} \mathrm{C}$ & $8.6^{\circ} \mathrm{C}$ & $17.1^{\circ} \mathrm{C}$ \\
\hline Global irradiation, annual sum & $976 \mathrm{kWh} / \mathrm{m}^{2}$ & $882 \mathrm{kWh} / \mathrm{m}^{2}$ & $1,530 \mathrm{kWh} / \mathrm{m}^{2}$ \\
\hline Diffuse irradiation, annual sum & $549 \mathrm{kWh} / \mathrm{m}^{2}$ & $515 \mathrm{kWh} / \mathrm{m}^{2}$ & $652 \mathrm{kWh} / \mathrm{m}^{2}$ \\
\hline
\end{tabular}


Subsequently, table 4 and table 5 unfolds the climatic conditions of Aberdeen city for the proposed system. Unlike Rome and London districts, Aberdeen region is one of the coldest parts of the United Kingdom, and may be described as cold climate, having cold temperature for majority of the time during the year. Nevertheless, there may be some hot days in the summer with temperatures above 20 degrees and very cold days in the winter. The average temperature during the year is around $8.6^{\circ} \mathrm{C}$ and the coldest month is around $-9{ }^{\circ} \mathrm{C}$.

Table 5 also unfolds the climatic conditions of Rome for the proposed system. Unlike London and Aberdeen, the district of Rome has a subtropical/ Mediterranean climate with some slight continentality elements. Winter is quite rainy and mild, nonetheless it can get cold at night. Winter season are cold in Rome, and the average low temperature drops to $2.8^{\circ} \mathrm{C}\left(37^{\circ} \mathrm{F}\right)$ during winter peak while the summer periods are sunny and hot with a few afternoon thunderstorms, and the average annual temperature is around $17.1^{\circ} \mathrm{C}$.

Solar fraction: fraction of solar energy to system

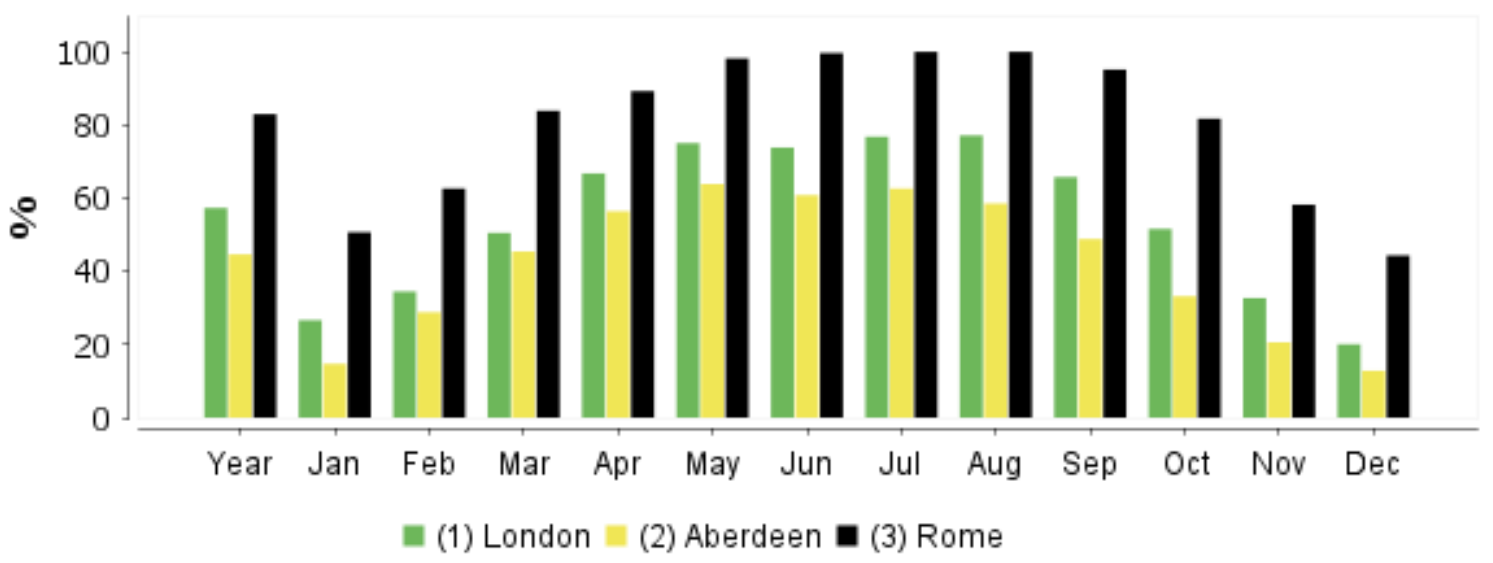

Figure 13. Fraction of solar energy to system

Solar thermal energy to the system

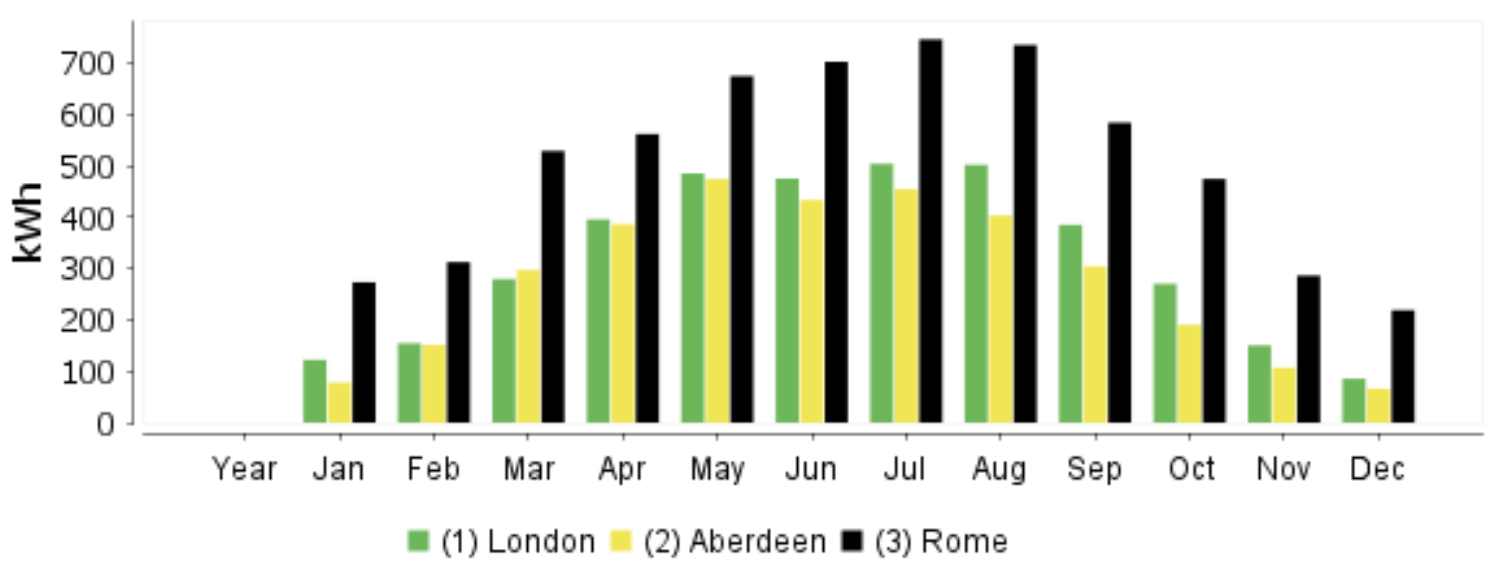

Figure 14. Solar thermal to the system 
Total fuel and/or electricity consumption of the system

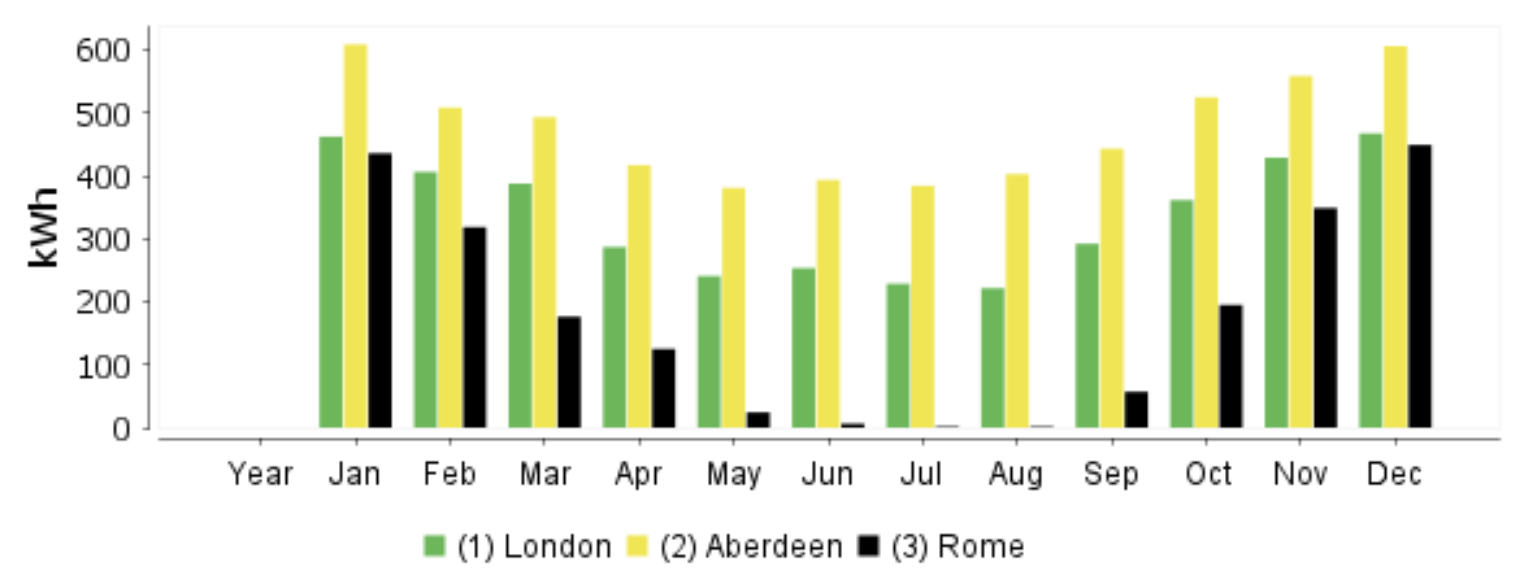

Figure 15. Fuel/electricity consumption of the system

The impact of climate on the energy performance is examined to determine which climates provide the greatest additional energy saving benefit and system performance from the configuration as a representation of climatic conditions in the United Kingdom/Europe. The comparison of energy results in association with the examined weather conditions of the districts of London, Aberdeen and Rome are shown in table 4. In each of these three cities, the figure 4 demonstrated that energy demands are expected to be covered to sustain the hot water demand in the bathroom. The figure 13 and figure 14 shows the amount of solar energy transferred to the system and its corresponding impact on energy savings as compared to the reference configuration. In Aberdeen, the configuration yields a reduced amount of energy savings of $15.1 \%$ as compared to the reference configuration and in Rome, the configuration provides $54 \%$ increased savings as compared to the reference system. Based on this figure, it is evident that the incremental savings can vary drastically depending on the location due to amount to radiation available.

Furthermore, the impact of location on system efficiency was examined for all the climates, table 4 shows that the system performance in Aberdeen provides less efficiency gain as compared to the reference system and Rome provide good efficiency gains as compared to the reference system with the largest incremental increased efficiency occurring in Rome.

Additionally, the figures 13,14, 15 and table 5.3 shows climate plays a large role in the magnitude of the incremental energy savings, however, it is clear that the locations of Rome yield the highest incremental savings, largely due to their relatively significant incident solar radiation. The extent of energy production yielded through solar collector and energy consumed in Rome are higher than in London while lesser in Aberdeen. This is due to several reasons. The first is a higher energy production from the same size of solar collector due to a higher solar irradiance. The second is that the solar collector energy production better matches the annual electricity demand. Finally, the third is a lower OFF time in the system because of freezing limitations. 


\section{Conclusion}

This study has demonstrated that integrated interactions of system components from holistic perspective is significant when considering the concept of solar hot water for use. This study has achieved high amount of energy savings (50-60\%) and high reduction in carbon emission $(1398 \mathrm{~kg})$ with system efficiency of 0.95. Academic studies from Jakobsons, 2015 and, Ayompe, 2015 have achieve a moderate system efficiency $26 \%$ and $31 \%$ respectively in terms of the energy savings and carbon emission savings they both search for, this is because efficiency of a single system component is constrained to the level of its operation as this is evidenced in their research outcome. The concept of holistic system integration does not only collectively enhance the efficiency of water and energy nexus but in addition can lessen cost and size of the system components when compared to enhancing or improving each component in the bathroom, subsequently the payback time for an integrated system can be greatly reduce due to the significant incentive provided by the government for the property owner and home developers to adjust to an integrated system.

Subsequently, parametric study demonstrated that high energy savings and system performance is also a function of location, load profiles and control which can offer a reduced level of energy consumption and rates of carbon emissions which in turn combat global warming and climate change.

\section{References}

Alessandro, F. (2020). Methods for the Sustainable Design of Solar Energy Systems for Industrial Process Heat. Sustainability, 12, 5127. https://doi.org/10.3390/su12125127

Arpke, A., \& Hutzler, N. (2006). Domestic Water Use in the United States. A Life-Cycle Approach. Journal of Industrial Ecology, 10(1-2), 169-183.

https://doi.org/10.1162/108819806775545312

Ayompe, L. (2015). Performance and Policy Evaluation of Solar Energy Technologies for Domestic Application in Ireland. Doctoral Thesis. Technological University Dublin.

Cheng, C.-L. (2002). Study of the Inter-Relationship between Water Use and Energy Conservation for a Building. Energy and Buildings, 34, 261-266.

https://doi.org/10.1016/S0378-7788(01)00097-4

DEFRA. (2008). Future Water: The Government's water strategy for England. [Online] Available: https://www.waterwise.org.uk/knowledge-base/future-water-the-governments-wate r-strategy-for-england-2008/

Duffie, A., \& Beckman, A. (2012). Solar Engineering of Thermal Processes (3rd ed.). https://doi.org/10.1002/9781118671603

Energy Saving Trust. (2013). At home with water. [Online] Available:

https://energysavingtrust.org.uk/sites/default/files/reports/AtHomewithWater\%287\%29.pdf

Ford, D., \& Berrang-Ford, L. (2011). Climate Change Adaptation in Developed Nations: From Theory to Practice. Springer: Dordrecht, The Netherlands. pp. 490. 
https://doi.org/10.1007/978-94-007-0567-8

Hobbi, A., \& Siddiqui, K. (2009). Optimal Design of a Forced Circulation Solar Water Heating System for a Residential Unit in Cold Climate Using TRNSYS. Solar Energy, 83, 700-714. https://doi.org/10.1016/j.solener.2008.10.018

Jenkins, J., Murphy, M., Sexton, M., Lowe, A., Jones, P., \& Kilsby, G. (2010). UK Climate Projections: Briefing report. [Online] Available: http://cedadocs.ceda.ac.uk/1321/

Koke, J., Kuhr, M., \& Clement, U. (2018). Automated Optimization of Solar-Thermal Systems Using Software in a Loop. American Journal of Energy Engineering, 5, 50-56. https://doi.org/10.11648/j.ajee.20170506.11

Kulkarni, N., Shireesh, B., \& Kedare, S. (2007). Determination of Design Space and Optimization of Solar Water Heating Systems. Science Direct, Solar Energy, 81, 958-968. https://doi.org/10.1016/j.solener.2006.12.003

Maria, J. (2015). Solar collectors' performance: A case study of a solar thermal heating system in a passive house dwelling. Maters thesis. Norwegian University of Science and Technology.

Oye, T. K., Gupta, N., Goh, K., \& Oye, T. T. (2020a). A Smart and Sustainable Concept for Achieving a Highly Efficient Residential Bathroom: A Literature Review. International Journal of Innovative Science and Research Technology, 5(3).

Oye, T. K., Gupta, N., Goh, K., \& Oye, T. T. (2020b). Design of a Smart and Intelligent Energy Efficient Controller for a Bathroom System. 9th International Conference on Renewable Energy Research and Application (ICRERA), Glasgow, UK. pp. 170-174. https://doi.org/10.1109/ICRERA49962.2020.9242819

Parker, J. M., \& Wilby, R. L. (2013). Quantifying Household Water Demand: A Review of Theory and Practice in the UK. Water Resour Manag, 27, 981-1011.

https://doi.org/10.1007/s11269-012-0190-2

Polysun program. (2020). Vela Solaris Polysun Designer Version. Design of reliable and holistic energy systems. For Buildings and districts with a future. [Online] Available: https://www.velasolaris.com/?lang=en

Ritchie, H., \& Roser, M. (2019). Energy Access. Energy production by region. Primary energy consumption by source, world, 1965 to 2019. [Online] Available:

https://ourworldindata.org/energy

United Nations Water and Energy sustainability. (2014). Managing the environmental impacts of water and energy. [Online] Available:

https://www.un.org/waterforlifedecade/pdf/01_2014_sustainability_eng.pdf

Water UK. (2016). Water resources long term planning framework (2015-2065). [Online] Available: https://www.water.org.uk/wp-content/uploads/2018/11/WaterUK-WRLTPF_FinalReport_FINAL-PUBLISHED-min.pdf 
Water Wise. (2009). The Water and Energy Implications of Bathing and Showering Behaviours and Technologies. [Online] Available:

https://www.waterwise.org.uk/wp-content/uploads/2018/02/Waterwise-2009_The-Water-andEnergy-Implications-of-Bathing-and-Showering-Behaviours-and-Technologies.pdf

\section{Copyright Disclaimer}

Copyright for this article is retained by the author(s), with first publication rights granted to the journal.

This is an open-access article distributed under the terms and conditions of the Creative Commons Attribution license (http://creativecommons.org/licenses/by/4.0/). 